\title{
Multistage Lung Cancer Detection and Prediction Using Deep Learning
}

\author{
Jay Jawarkar ${ }^{1}$, Nishit Solanki ${ }^{1}$, Meet Vaishnav ${ }^{1}$, Harsh Vichare ${ }^{1}$, Dr. Sheshang Degadwala ${ }^{2}$ \\ 1U.G. Scholar, Sigma Institute of Engineering, Vadodara, Gujarat, India \\ ${ }^{2}$ Associate Professor, Sigma Institute of Engineering, Vadodara, Gujarat, India
}

\begin{abstract}
Article Info

Volume 8 Issue 2

Page Number: 54-60

Publication Issue :

March-April-2021

Article History

Accepted : 01 March 2021

Earlier, the progression of the descending lung was the primary driver of the chaos that runs across the world between the two people, with more than a million people dies per year goes by. The cellular breakdown in the lungs has been greatly transferred to the inconvenience that people have looked at for a very predictable amount of time. When an entity suffers a lung injury, they have erratic cells that clump together to form a cyst. A dangerous tumor is a social affair involving terrifying, enhanced cells that can interfere with and strike tissue near them. The area of lung injury in the onset period became necessary. As of now, various systems that undergo a preparedness profile and basic learning methodologies are used for lung risk imaging. For this, CT canal images are used to see and save the adverse lung improvement season from these handles. In this paper, we present an unambiguous method for seeing lung patients in a painful stage. We have considered the shape and surface features of CT channel pictures for the sales. The perspective is done using undeniable learning methodologies and took a gender at their outcome.
\end{abstract}

Published : 08 March 2021
Keywords : Decision Tree, KNN, RF, DF, Machine Learning

\section{INTRODUCTION}

The crumbling of the cells in the lungs is the adjustment which starts in the lungs. This is the second most legitimate issue among individuals. Exactly when signs are found close, risky lung improvement tests are made to pick such a lung issue and on karma off that it has dispersed. Without a doubt while tending to the improvement escalate, this is stated as metastasis. [10]. Early known of lung cyst is finished by utilizing imaging systems, for example, Computed Tomography (CT), Sputum Cytology, Chest X-shaft and Magnetic Resonance Imaging
(MRI). ID It is proposed that the tumor be assembled into two classifications (1) non-pathogenic (liberal) and (2) dangerous (threatening) [11]. The issue is the flimsiest illness in the clinical field, as it should be found in the pre-minimization phase of the qualities that are viewed as the end and treatment [12]. This adjustment in lung cells happens regularly when individuals take in risky and hurtful substances. Regardless of whether you have been utilized to these substances for quite a long while or not, you are currently in danger of improving lung harm. Along these lines, it is important to portray the periods of the lung. 


\section{Types of Stages [14]}

Stage I: Contamination is inside the lung, regardless, it would not disperse to outer the lung. The key cyst is $3 \mathrm{~cm}$ or less. Activity to slaughter a piece of the lung might be all you need. Eradication may in like way be suggested, particularly on the off chance you're at very close chance of repeat. Stage I signs are the terseness on inhale or exhales, rapines, hacking, and chest excruciation.

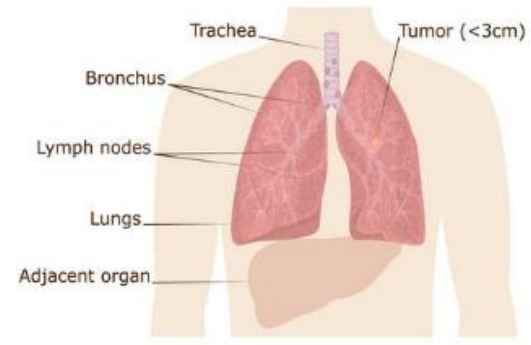

Figure 1. Stage I [13]

Stage II: Contamination is inside the lung and adjoined to lymph focus center interests. Elemental cyst(sore) is up to 3 to $5 \mathrm{~cm}$. You may in requirement of clinical surgery to clear out part or the proportion of your lung. Eradication is by and large proposed. Stage II results are Choke up blood or natural fluid, Wheezing and briskness of breath, Weight mishap and loss of craving, Chest torture that lessens when inhaling and exhaling altogether or laughing

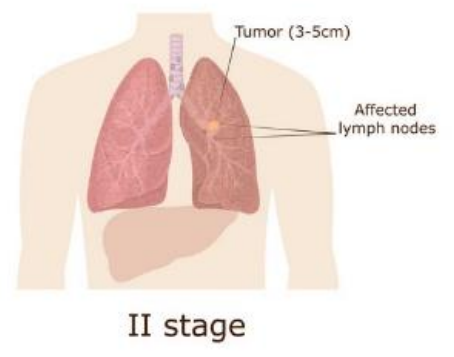

Figure 2. Stage II [13]

Stage III: Contamination is inside the lung and lymph center concentrations in the chest. Elemental cyst is 5 $\mathrm{cm}$ or exceeds. You might in requirement of mix of eradication, clinical surgery, and emission treatment.
Stage III signs are Trouble breathing, being panting for air or gasping for air, Pain in chest region, wheezing sound when inhaling and exhaling, Voice Becomes hoarser, Anonymous drop in weight, Bone anguish, Agony in the forehead.

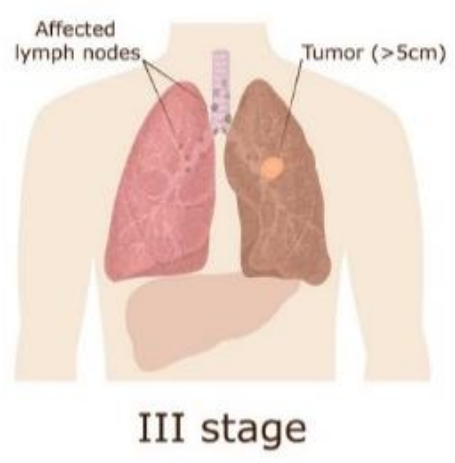

Figure 3. Stage III [13]

Stage IV: Contamination is dispersed to the two lungs, the area around the lungs, or to cleared out organs. Indicative cyst is over $7 \mathrm{~cm}$. Choices to do clinical surgery, radiation, eradication, made treatment, and immunotherapy. Stage IV appearances are Body a beating sickening quality, Faintness, cerebral agonies, Ascending or diminished pulsating.

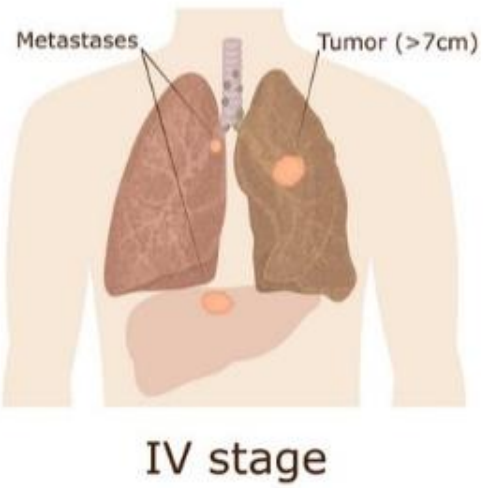

Figure 4. Stage IV [13]

\section{RELATED WORKS}

Janee Alam1 et al.[1] depicts lung malignant growth multistage location utilizing this strategy are SVM Classifier, GLCM highlight, and Watershed Transform. This paper confinements are, little dataset, 
low precision, and utilized huge element measurements.

Emine CENGİL et al.[2] depict the profound learning way to deal with lung malignancy and they utilized Convolution Neural Network (CNN). This paper has a few restrictions are grouped just dangerous or not, additionally improve engineering and framework to improve the huge dataset.

Manatee Kurkure1 et al.[6]. utilized Genetic applicant Group search (GCGS) Algorithm and Naïve base classifier. This Research has a few confinements are improved grouping strategies, low exactness and countless datasets ought to be required for better outcomes.

Suren Makajua et al.[7].used water concealed Transform and SVM Classifier. This paper has a few constraints don't group the level of the knob, not arrange various stages and furthermore improve the exactness must be expanded by pre-handling.

Mehdi Fatan Serj et al.[3] portray DCNN for the lung malignant growth recognition approach and they have utilized the DCNN classifier. This paper has a few impediments are division isn't done, large component vector and GPU are required to run the framework.

F. Ghazvinian Zanjani1 et al.[8] depict disease location in Mass Spectrometry picture information utilizing RNN(Recurrent Neural Network). A few constraints of this paper are improved engineering of $\mathrm{RNN}$, Improve order results, and increment execution.

Moffy Vas et al.[4] depicts for identifying lung disease techniques that they have utilized are Morphological, Harrick, GLCM, and ANN. This paper has a few impediments are Morphological division require to change organizing component and they group just two classes.

\section{BACKGROUND}

In this part concise clarify about tumor highlights. Chiefly two kinds of highlight shape and surface are utilized for stage tumor grouping

\section{A. Feature Extraction:}

It depicts the proper shape and surface data contained in a model with the target that the errand of preparation the model is explained by a fitting procedure. In structure assertion and in picture directing, entwine extraction is an astounding kind of dimensionality decay. Right when highlights have been taken out, they might be utilized to make AI models

Table I: Shape Feature

\begin{tabular}{|l|l|}
\hline \multicolumn{2}{|c|}{ Shape Features [5] } \\
\hline Area & $\begin{array}{l}\text { The zone is the quantity } \\
\text { of the pixel in the shape. } \\
\text { The absolute expanse (or } \\
\text { the area of the square } \\
\text { unit) that involved in a } \\
\text { shut expanse is name as } \\
\text { area. }\end{array}$ \\
\hline Perimeter & $\begin{array}{l}\text { The border (length) is the } \\
\text { number of pixels in the } \\
\text { constraint of the thing. } \\
\text { The } \\
\text { partition of the shut shape } \\
\text { (or figure) is named as } \\
\text { line. The line of the } \\
\text { square shape is the all out } \\
\text { of the length's things } \\
\text { being what they are. }\end{array}$ \\
\hline Eccentricity & $\begin{array}{l}\text { Eccentricity is the ratio } \\
\text { of the length of the short } \\
\text { axis to the length of the } \\
\text { long axis of an object: }\end{array}$ \\
\hline
\end{tabular}




\begin{tabular}{|l|c|}
\hline & $\begin{array}{c}\text { Eccentricity }= \\
\text { axislength }(\min )\end{array}$ \\
axislength $(\max )$
\end{tabular}

Table II: Texture Feature

\begin{tabular}{|c|c|}
\hline \multicolumn{2}{|r|}{ Texture Features [4] } \\
\hline Contrast & $\begin{array}{l}\text { Contrast is defined as the } \\
\text { difference between the highest } \\
\text { and lowest intensity value of } \\
\text { the image. } \\
\text { CON= } \sum_{I} \sum_{J}(i-j)^{2} p(i, j)\end{array}$ \\
\hline Correlation & $\begin{array}{l}\text { Correlation is the process of } \\
\text { moving a filter mask often } \\
\text { referred to as kernel over } \\
\text { the image and computing the sum } \\
\text { of products at each } \\
\text { location. Correlation is the } \\
\text { function of displacement of the } \\
\text { filter. } \\
\text { Correlation } \\
\sum_{i} \sum_{j}\left(i-\mu_{i}\right)\left(j-\mu_{j}\right) N_{d}(i, j) \\
\sigma_{i} \sigma_{j}\end{array}$ \\
\hline Energy & $\begin{array}{l}\text { Energy is used to describe a } \\
\text { measure of "information" when } \\
\text { formulating an operation under a } \\
\text { probability framework such as } \\
\text { MAP (maximum a priori) } \\
\text { estimation in conjunction with } \\
\text { Markov Random Fields. } \\
\text { Energy= } \sum_{i} \sum_{j} N_{d}(i, j)\end{array}$ \\
\hline Homogeneity & $\begin{array}{l}\text { Homogeneity reflects } \\
\text { the homogeneity of } \\
\text { image textures and scaled the } \\
\text { local changes of image texture. } \\
\text { High values } \\
\text { of homogeneity denote the } \\
\text { absence of intra-regional changes }\end{array}$ \\
\hline
\end{tabular}

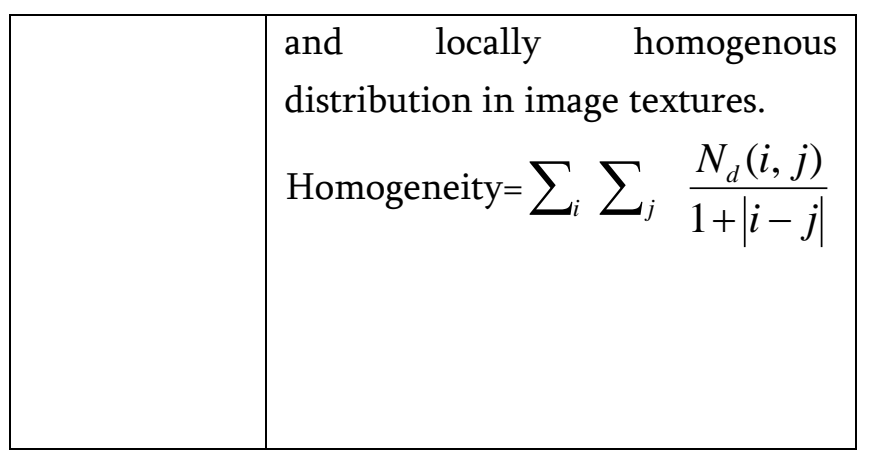

\section{PROPOSED SYSTEM}

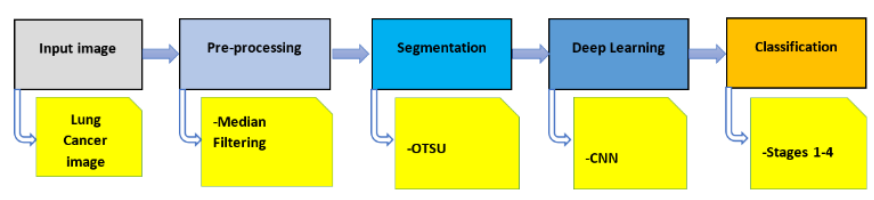

Figure 5. Proposed system

From the above figure first thing, we need to expect the responsibility of the lung dangerous movement picture. By at that point, after we will be pre dealing with that picture by applying focus confining for diminishing exacerbation with the target that picture can be ceaselessly sensible. After Pre-organizing finished then division applies. Picture Segmentation of lung handles in CT pictures is utilized to improve possible result of pixels respect thresholding is utilized. Afterimage division, we utilized segment extraction shape and surface association. Hereafter, we get continuously careful outcomes in lung stage interest. For Classification purposes, we use the basic learning CNN classifier which is the greatest classifier.

\section{A. Input}

The detailed model is a little subspace of replica from the ailment imaging record. They join inside cut of all CT pictures taken where liberal age, thinking, and partition names could be extracted. This outcome in 475 layouts from 69 amazing patients.

\section{- Data Header}

Images (DICOM, 18.3GB)

Tissue Slide Images (web)

Clinical Data (TXT)

Genomics (web) 


\section{- TCIA Archive Link}

"https://wiki.cancerimagingarchive.net/display/Public /TCGA-LUAD.”

\section{B. Pre-Processing:}

A separation of $3 \times 3$ is enforced on the picture where the focal pixel respect is unstuck with the middle assessment of the relating pels which assists with getting muddled pixel freed from unessential worth

\begin{tabular}{|l|l|l|}
\hline 252 & 255 & 252 \\
\hline 252 & 2 & 255 \\
\hline 255 & 255 & 253 \\
\hline
\end{tabular}

Figure 6. Median Filtering Matrix

Neighborhood value:

2,252,252,252,253,255,255,255,255

Equidistant value: 253

Here the estimation of 2 is supplanted with the worth 253 which drops commotion and fills the haze partition in the picture.

\section{Segmentation:}

OTSU method is perhaps the best method for picture thresholding.

After Changing greyscale picture to monochrome is a standard picture setting up the endeavor. Otsu's policy, named after its producer Nobuyuki Otsu, is one of the particular banalization assessments. At all astonishing turn of events, the figuring restores a solitary power limit that different pels into two classes, cutting edge, and foundation.

\section{Feature Extraction:}

we have utilized a blend of two-area essentially contours and area. Perfectly healthy integrate, we have a used area, line, and rarity. While on a shallow level we have used GLCM lineament for instance depravity, entropy, alliance, and Homogeneity. So complete part of the subdivisions is seven. Which will use for the alternation over the model.

\section{E. Deep Learning:}

Deep learning is a subset of AI where artificial neural Algorithms mixed by the human intellect, acquire from a ton of data. Huge learning grants machines to oversee convoluted issues disregarding, while using a Data set that is absurdly uncommon, disorganized and between related. Computationally drew in model Deep learning applications are used in endeavors from motorize going to Medical contrivance. CNN [2,3]: In Deep learning, a convolutional neural network (CNN, or ConvNet) is a class of Deep neural network, most reliably applicable to investigating idealistic. CNNs are regularized variety of multi-facet perceptron. CNN are excellent kind of Feed-Forward Artificial Neural Network that are everything viewed as used for picture enclave work. [10]

\section{F. Stages Classification:}

Here we are segregating four stage of Lung Tumor: (1) Stage-I, (2) Stage-II, (3) Stage-III and (4) Stage-IV.

\section{EXPERIMENTAL AFTERMATH AND SCRUTINY}

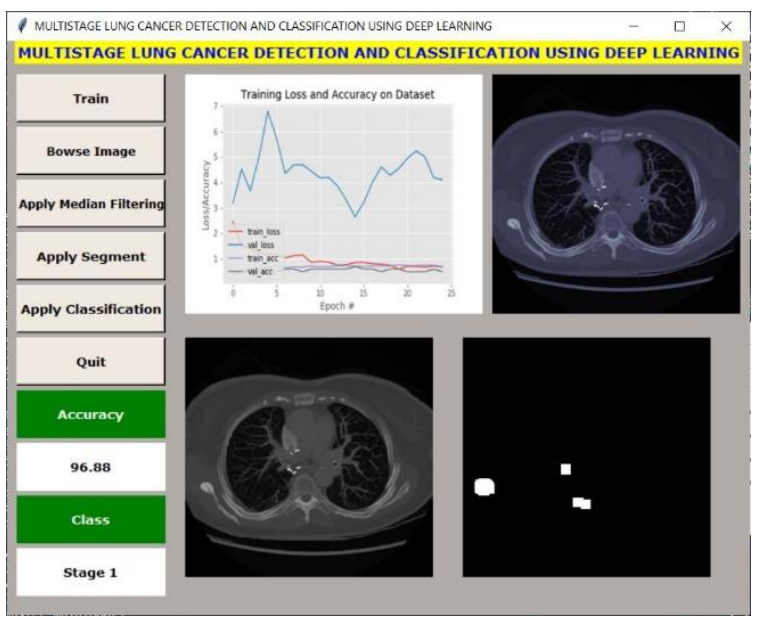

Figure 8: Stage I classification 


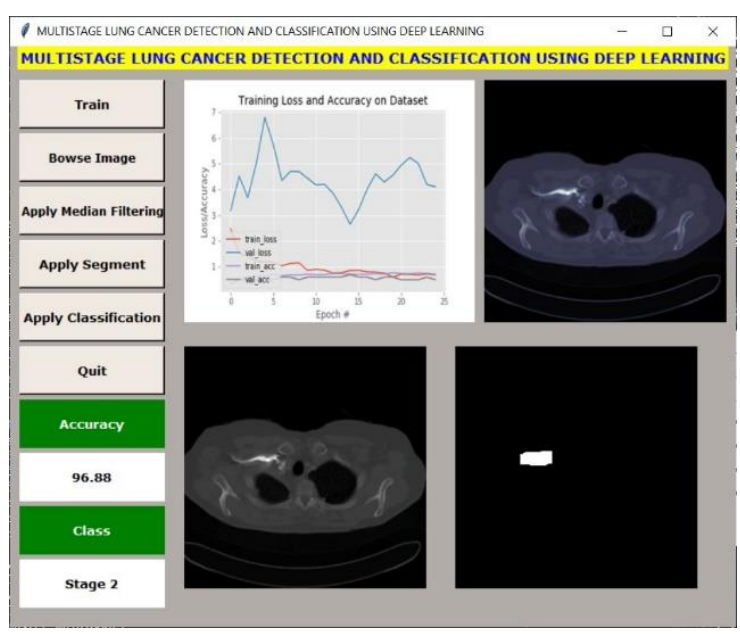

Figure 9: Stage II classification

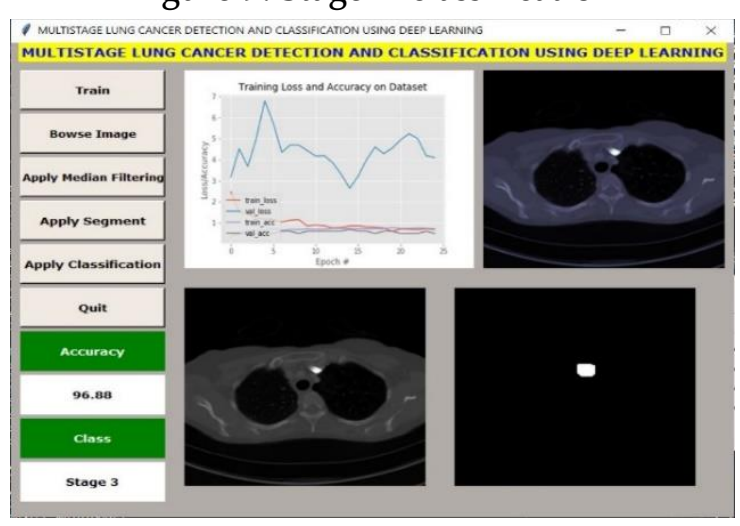

Figure 10: Stage III classification

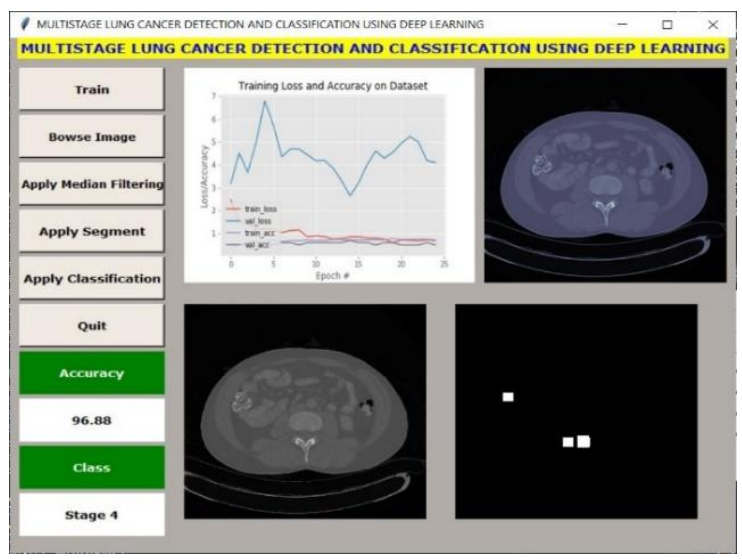

Figure 11: Stage IV classification

As appeared in Table IV shows near investigation utilizing shape and Texture include with various classifiers among them Decision Tree give player execution.
Table III. Accuracy Comparision

\begin{tabular}{|l|c|c|}
\hline \multicolumn{1}{|c|}{ Authors } & Technique Applied & Accuracy \\
\hline $\begin{array}{l}\text { Janee et al, } \\
\text { Sabrina et al }\end{array}$ & SVM classifier & $87 \%$ \\
\hline $\begin{array}{l}\text { Propose } \\
\text { Algorithm }\end{array}$ & CNN classifier & $\mathbf{9 6 . 8 8 \%}$ \\
\hline
\end{tabular}

\section{CONCLUSION}

NSCLC Stage request is needing for early end. Past scheme depends upon depict basically cell breakdown in the lungs type. It would not give stage data. For shape comprise we will resort to segmentation to social occasion and after that deep learning for stage prediction. In this appraisel, we sum up various kinds of cell breakdown in the lungs stages for request. Deep learning procedure gives $96.88 \%$ precision

\section{REFERENCES}

[1]. J. Alam, A. Hossan and S. Alam, "Multi-Stage Lung Cancer Detection and Prediction Using Multi-class SVM Classifie," Int. Conf. Comput. Commun. Chem. Mater. Electron. Eng. IC4ME2 2018, pp. 1-4, 2018.

[2]. E. Cengil and A. Çinar, "A Deep Learning Based Approach to Lung Cancer Identification," 2018 Int. Conf. Artif. Intell. Data Process. IDAP 2018, 2019.

[3]. B. Lavi, “A Deep Convolutional Neural Network for Lung Cancer Diagnostic," pp. 1-10.

[4]. A. Dessai and M. Vas, "Lung cancer detection system using lung CT image processing," 2017 Int. Conf. Comput. Commun. Control Autom., pp. 1-5, 2017.

[5]. A. Alsadoon, S. Makaju, P. W. C. Prasad, A. K. Singh, and A. Elchouemi, "Lung Cancer Detection using CT Scan Images," Procedia Comput. Sci., vol. 125, no. 2009, pp. 107-114, 2018. 
[6]. M. Kurkure and A. Thakare, "Classification of Stages of Lung Cancer using Genetic Candidate Group Search Approach," IOSR J. Comput. Eng., vol. 18, no. 05, pp. 07-13, 2016.

[7]. A. Srinivasan A. Asuntha, A. Brindha and S. Indirani, "Lung cancer detection using SVM algorithm and optimization techniques," J. Chem. Pharm. Sci., vol. 9, no. 4, pp. 3198-3203, 2016.

[8]. F. G. Zanjani et al., "CANCER DETECTION IN MASS SPECTROMETRY IMAGING DATA BY RECURRENT NEURAL NETWORKS Eindhoven University of Technology, SPSVCA , 5612 AJ Eindhoven, The Netherlands Maastricht Multimodal Molecular Imaging Institute , University of Maastricht , The Netherlan," 2019 IEEE 16th Int. Symp. Biomed. Imaging (ISBI 2019), no. Isbi, pp. 674-678, 2019.

[9]. M. Bharathi, S. Sasikala , and B. R. Sowmiya, "Lung cancer detection and classification using deep CNN,” Int. J. Innov. Technol. Explor. Eng., vol. 8, no. 2S, pp. 259-262, 2018.

[10]. X. K. Luo, Q. Z. Song, L. Zhao and X. C. Dou, "Using Deep Learning for Classification of Lung Nodules on Computed Tomography Images," J. Healthc. Eng., vol. 2017, 2017.

[11]. A. Teramoto et al., "Automated classification of benign and malignant cells from lung cytological images using deep convolutional neural network," Informatics Med. Unlocked, vol. 16, no. May, p. 100205, 2019.

[12]. C. A. O'Dowd, S. Tsim, R. Milroy, and S. Davidson, "Staging of non-small cell lung cancer (NSCLC): A review," Respir. Med., vol. 104, no. 12, pp. 1767-1774, 2010.

[13]. Scio21,Four stage of lung cancer vector image, https://www.vectorstock.com/royalty-freevector/four-stages-of-lung-cancer-vector22417619

[14]. Winfield Boerckel, LCSW-R,Lung Cancer Program Coordinator, Cancer Care, Lung cancer101, https://www.lungcancer.org/find_information/p ublications/163-lung_cancer_101/265what_is_lung_cance

\section{Cite this article as :}

Jay Jawarkar, Nishit Solanki, Meet Vaishnav, Harsh Vichare, Dr. Sheshang Degadwala, "Multistage Lung Cancer Detection and Prediction Using Deep Learning", International Journal of Scientific Research in Science, Engineering and Technology (IJSRSET), Online ISSN : 2394-4099, Print ISSN : 2395-1990, Volume 8 Issue 2, pp. 54-60, March-April 2021. Available at

doi : https://doi.org/10.32628/IJSRSET218217

Journal URL : https://ijsrset.com/IJSRSET218217 